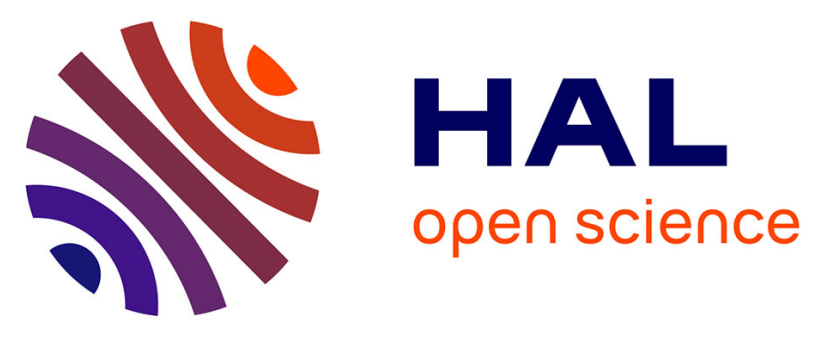

\title{
Observation opportunities for Mars atmosphere with the MIRS instrument aboard the Martian Moon eXploration mission
}

\author{
Alain Doressoundiram, Thomas Gautier, Maria Antonietta Barucci, Shohei \\ Aoki, Jérémie Lasue, Jean-Michel Réess, Pernelle Bernardi, Michel Le Du, \\ Eric Sawyer, Takahiro Iwata, et al.
}

\section{To cite this version:}

Alain Doressoundiram, Thomas Gautier, Maria Antonietta Barucci, Shohei Aoki, Jérémie Lasue, et al.. Observation opportunities for Mars atmosphere with the MIRS instrument aboard the Martian Moon eXploration mission. 15th Europlanet Science Congress 2021, Sep 2021, Virtual Meeting, France. 10.5194/epsc2021-124 . insu-03567034

\section{HAL Id: insu-03567034 https://hal-insu.archives-ouvertes.fr/insu-03567034}

Submitted on 11 Feb 2022

HAL is a multi-disciplinary open access archive for the deposit and dissemination of scientific research documents, whether they are published or not. The documents may come from teaching and research institutions in France or abroad, or from public or private research centers.
L'archive ouverte pluridisciplinaire HAL, est destinée au dépôt et à la diffusion de documents scientifiques de niveau recherche, publiés ou non, émanant des établissements d'enseignement et de recherche français ou étrangers, des laboratoires publics ou privés. 
EPSC Abstracts

Vol. 15, EPSC2021-124, 2021, updated on 11 Feb 2022

https://doi.org/10.5194/epsc2021-124

Europlanet Science Congress 2021

(C) Author(s) 2022. This work is distributed under

the Creative Commons Attribution 4.0 License.

\title{
Observation opportunities for Mars atmosphere with the MIRS instrument aboard the Martian Moon eXploration mission
}

\author{
Alain Doressoundiram ${ }^{1}$, Thomas Gautier ${ }^{2}$, Maria Antonietta Barucci ${ }^{1}$, Shohei Aoki ${ }^{3}$, Jérémie \\ Lasue $^{4}$, Jean-Michel Réess ${ }^{1}$, Pernelle Bernardi ${ }^{1}$, Michel Le Du ${ }^{5}$, Eric Sawyer ${ }^{5}$, Takahiro Iwata ${ }^{3}$, \\ Hiromu Nakagawa ${ }^{6}$, Tomoki Nakamura ${ }^{6}$, and the MIRS Team* \\ ${ }^{1}$ LESIA-Observatoire de Paris, Université PSL, CNRS, Sorbonne Université, Université de Paris, Meudon, France \\ (alain.doressoundiram@obspm.fr) \\ ${ }^{2}$ LATMOS, CNRS, Sorbonne Université, UVSQ-UPSaclay, Guyancourt, France \\ ${ }^{3}$ ISAS, JAXA, Sagamihara 252-5210, Japan \\ ${ }^{4}$ Observatoire Midi-Pyrenees - Universite Paul Sabatier - IRAP, 31028 Toulouse \\ ${ }^{5}$ CNES, Toulouse, France \\ ${ }^{6}$ Tohoku University, Sendai 980-8578, Japan \\ ${ }^{*}$ A full list of authors appears at the end of the abstract
}

The Martian Moon exploration mission (MMX), currently developed by the Japan Aerospace Exploration (JAXA) will aim at studying Mars satellites and return samples from Phobos to decipher the history of the Martian system. MMX mission is to be launched in September 2024 and arrive in Mars system on August 2025, will stay three years in Quasi Satellite Orbits (QSO) around Phobos, and will land for several hours on Phobos to collect at least $10 \mathrm{~g}$ of Phobos regolith before returning to Earth.

Among the mission instrument suite is the near-Infrared Spectrometer MIRS (MMX InfraRed Spectrometer) provided by CNES and built at LESIA-Paris Observatory in collaboration with four other French laboratories (LAB, LATMOS, LAM, IRAP-OMP) and in close collaboration with JAXA and MELCO. MIRS is an imaging spectrometer from 0.9 to $3.6 \mu \mathrm{m}$, with a spectral resolution better than $20 \mathrm{~nm}$. The IFOV is $0.35 \mathrm{mrad}$ and FOV of $+/-1.65^{\circ}$. The SNR is higher than 100 up to $3.2 \mu \mathrm{m}$ in a maximum integration time less than 2s. For Mars observation MIRS is expected to perform observations at $10 \mathrm{~km}$ spatial resolution, with a spectral radiometric absolute and relative accuracies of $10 \%$ and $1 \%$ respectively.

Given MIRS spectral range, expected Signal-to-Noise ratio, and observation windows, a certain numbers of high priority targets have been set to achieve MMX goal of Constrain transport processes for dust and water near the Martian Surface, continuous observations of the mid-to low-latitude distributions of dust storms, ice clouds and water vapor in the Martian atmosphere (Barucci et al. 2021, Ogohara et al. 2021), summarized in Table 1. Simulated spectra of Martian atmosphere as observed by MIRS are provided in Figure 1.

Table 1: List of MIRS main science targets for Mars observations (adapted from Barucci et al. 2021).

Target

Parameters

Spectral range 
Ice cloud formation and evolution Water ice Dust clouds / storms formationDust and evolution

Water cycle Atmospheric composition $\mathrm{CO}$ dynamics H2O vapor andSurface pressure

\section{$2.3 \mu \mathrm{m}$}

Limb observations for middleO $_{2}$ day-glow atmosphere
$1.5,2$ and $3 \mu \mathrm{m}$

$\mathrm{CO}_{2}$ band $@ 2.7 \mu \mathrm{m}$

0.9-3.6 $\mu \mathrm{m}$ continuum

$2.6 \mu \mathrm{m}$

$\mathrm{CO}_{2}$ band @ $2.0 \mu \mathrm{m}$

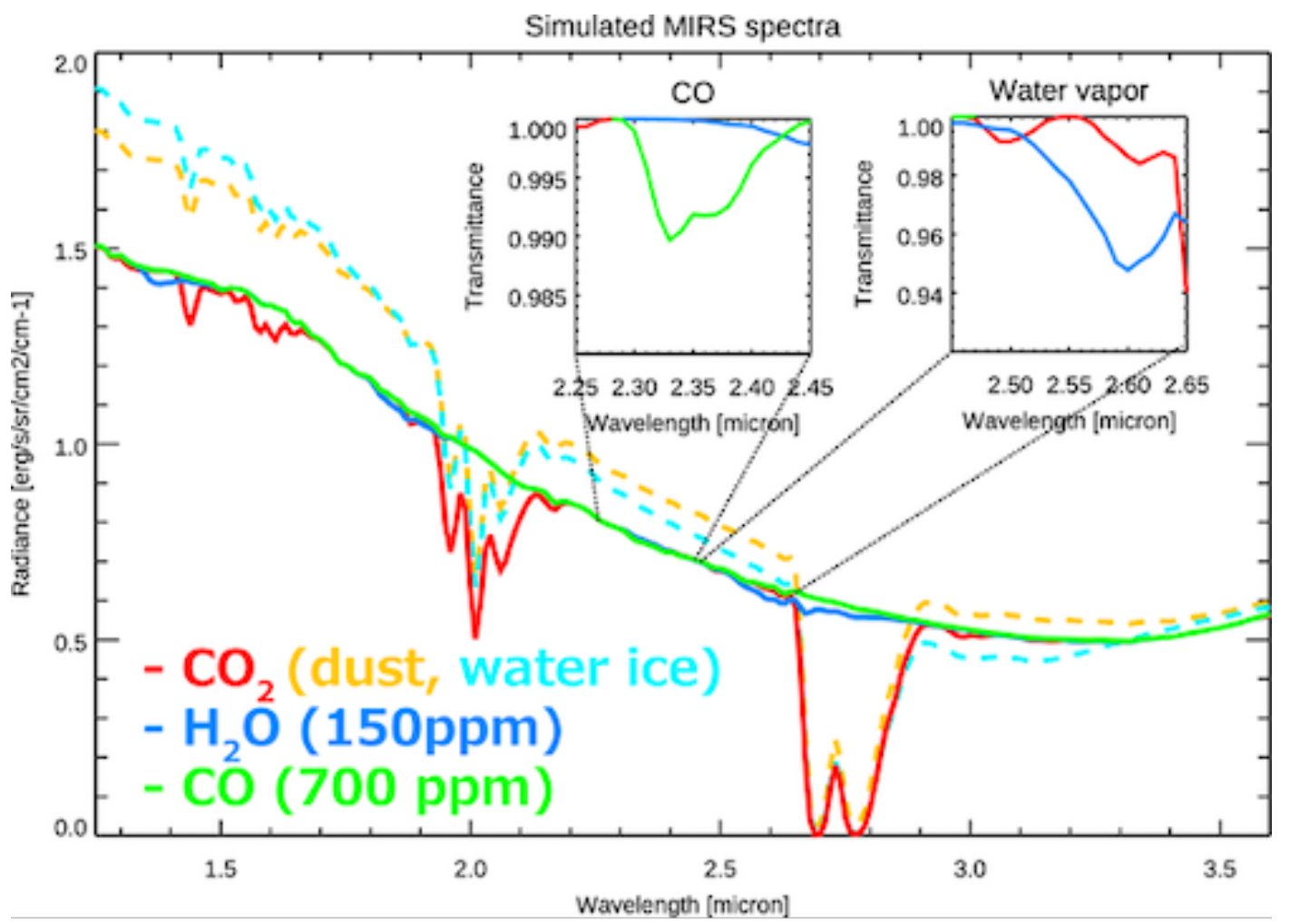

Figure 1: Simulated MIRS spectra for typical Mars observation (from Barucci et al. 2021). Plain curves correspond to clear sky conditions, and the dashed ones include the effects of dust or water ice clouds. For gases, $\mathrm{CO} 2, \mathrm{CO}$, and water vapor are calculated separately and reported in red, orange, and blue curves, respectively.

MMX QSO around Phobos will result in a quasi-circular orbit around Mars with a period of $\sim 7 \mathrm{~h}$, providing more than 3 hours window to Mars observation when Phobos observation is not possible. Several observation strategies, still in discussion, will be possible to maximize either temporal or spatial coverage of Mars and its atmosphere by MIRS. These strategies span from observations with a 30 minutes temporal resolution of a limited zone, to a complete coverage for low and mid latitude in a few orbits (Ogohara et al. 2021, Barucci et al. 2021). Limb observations may also be performed to obtain high vertical resolution observations of the Martian atmosphere.

MIRS observations will provide further constraints on dust and water transport processes in the Martian atmosphere, by monitoring the distributions of dust content and storms, water ice clouds and water vapor. $\mathrm{CO}_{2}$ (and thus pressure) will be monitored through the $\mathrm{CO}_{2} 2.0 \mu \mathrm{m}$ band. Water vapor will be monitored on a daily basis using its $2.6 \mu \mathrm{m}$ band (Maltagliati et al. 2008) and water ice clouds through their spectral features between 0.9 and $3.6 \mu \mathrm{m}$ (Olsen et al. 2019). MIRS should also be able to detect $\mathrm{CO} 2.35 \mu \mathrm{m}$ and $\mathrm{O}_{2}$ at $1.27 \mu \mathrm{m}$. MIRS spectra will also allow for estimations of the 
water adsorbed in the surface regolith. Finally, MIRS will be operated in close collaboration with the OROCHI (Optical Radiometer composed of Chromatic Imagers) and TENGOO (Telescopic Narrow Angle Camera) instruments. This will enable efficient monitoring and reactivity to investigate short lifespan events in Martian atmosphere. This will also render possible the investigation of $\mathrm{CO}_{2} \mathrm{Clouds}$ following the procedure proposed by Vincendon et al. 2011 for Mars Express observations.

The reflectance spectrum from the light backscattered by atmospheric aerosols can be obtained by comparing successive observations of identical zones on Mars within a short time and with varying phase angles. Such a set of measurements permits to decorrelate the surface reflectance signal from the light scattered by the aerosols suspended in the atmosphere and gives information on the aerosols size and their composition properties averaged over the line of sight. Previous measurements showed a particle size distribution having an effective radius of $1.2 \pm 0.2 \mu \mathrm{m}$ (Erard et al. 1994). The retrieved parameters include the scattering albedo, the phase function of the aerosols, the optical thickness, $\mathrm{T}$, of the atmosphere at the time of observation and the aerosols size distribution.

In summary, MIRS observations, together with the ones from MSA, OROCHI and TENGOO, will help better understand the interdependencies of species and their roles in the Martian water, $\mathrm{CO}_{2}$ and dust cycles, thanks to long term monitoring of these key constituents of Mars atmosphere.

\section{References}

Barucci et al. 2021, MIRS an Imaging Spectrometer for the MMX mission, accepted for publication in Earth Planets and Space

Erard, S., Mustard, J., Murchie, S., Bibring, J. P., Cerroni, P., \& Coradini, A. (1994). Martian aerosols: Near-infrared spectral properties and effects on the observation of the surface. Icarus, 111(2), 317-337.

Ogohara et al. 2021, The Mars system revealed by the Martian Moons exploration mission, accepted for publication in Earth Planets and Space

Vincendon et al. 2011, New near-IR observations of mesospheric CO2 and H2O clouds on Mars, JGR Planets 116, 0-02.

MIRS Team: 